\title{
Potential application of liquid dye penetrants for serial number restoration on firearms
}

Philip Maynard ${ }^{1}$, Kyle Skinner ${ }^{1}$, Matthew Bolton ${ }^{2}$ Sébastien Moret $^{1}$

1 University of Technology Sydney, Centre for Forensic Science, Broadway, 2007, Australia

2 Forensic Ballistics Investigation Section, New South Wales Police Force Forensic Services Group, Surry Hills 2010 Australia

${ }^{*}$ Corresponding Author

Dr Philip Maynard Philip.Maynard@uts.edu.au 


\begin{abstract}
Chemical reagents for serial number restoration are designed to exploit the plastic deformation zone below the obliterated serial number. Most techniques in operational use are variants of Fry's Reagent. This technique uses toxic, corrosive chemicals and requires a skilful operator in the laboratory. Fry's Reagent can also be destructive of the firearm due to rusting. In an attempt to find a non-toxic, non-destructive alternative to Fry's Reagent, this project tested the use of liquid dye penetrants (LDPs), a non-destructive examination technique to detect cracks and imperfections used in the welding industry, for the restoration of obliterated serial numbers. Steel plates bearing an obliterated serial number with a range of obliteration depths were subjected to LDP treatment under various treatment conditions.

The results using LDPs were negative for all obliteration depths and all test conditions attempted. Some of the serial numbers were subsequently restored successfully with Fry's reagent, proving that the plastic deformation zone was present on the steel plates below the obliteration. Further work to develop a non-toxic, non-destructive serial number restoration process will be undertaken.
\end{abstract}

\title{
Keywords
}

Firearms, serial number restoration, Fry's reagent, chemical etching, liquid dye penetrants

\section{Introduction}

Serial numbers

There is a clear need for forensic examiners to identify firearms involved in criminal matters as it can determine the ownership of a firearm and can eventually link the perpetrators to a scene. Significant challenges are experienced if a seized firearm has had the serial numbers destroyed by means of filing or drilling out these identifying characteristics to avoid association with the firearm. However, obliteration of the serial number is unsuccessful in some cases as the plastic deformation caused by the stamping process extends deeper than the visible markings [1-4].

The region where the metal is permanently deformed by the stamping process is called the influenced depth [2], as seen in Figure 1. The depth of this region varies, depending on the serial number manufacturing process, as well as the composition of the firearm [1]. Three methods exist for creating serial numbers: stamping of the serial number $[2,5]$, laser engraving [1] and carving [6], each having a different effect on the crystal lattice of the 
material when it is marked [3]. Regardless of the method, the imprinting must be to a minimum depth of 0.003 inch $(0.0762 \mathrm{~mm})$ with the print being no smaller than 1/16 inch (1.5875 mm) according to the Bureau of Alcohol, Tobacco, Firearms and Explosives (ATF) [7].

Figure 1: cross-sectional illustration of a stamped piece of metal, demonstrating the plastic deformation zone underneath an imprint

\section{Chemical techniques used for serial number restoration}

There are a variety of reagents for the restoration of serial numbers [3, 5, 6, 8-15]. When selecting a reagent the substrate material is one of the main factors. The first method using "deep-etching" solutions was developed in 1919 by Waring and Hofaman using one part hydrochloric acid and three parts water [16,17]. It was improved upon in 1921 to consist of 1:1 hydrochloric acid and water heated to $71{ }^{\circ} \mathrm{C}$. Watertown Arsenal developed a variant that consisted of 38 parts hydrochloric acid, 12 parts sulfuric acid and 50 parts water. This reagent produced the sharpest restorations at the time [18].

Copper-containing reagents predate the development of hot-acid etching. Heyn's reagent was the first to be developed; the other reagents were modified from this method. Stead's reagent was the most widely-used reagent after Heyn's [16]. Magnusson in 1947 tested the Stead reagent for revealing the primary structure of welds and recommended that the surface be prepared by polishing before treatment with the reagent [16].

Other widely used reagents at the time were the Oberhoffer's reagent and Fry's reagent, first published by Fry in 1921 [16]. Fry's Reagent and derivatives involve an acid-etching with ferric or cupric chloride; copper sulphate has also been used in conjunction with an acid wash [5].

Fry's reagent and related variants are the main etching techniques used on steel surfaces today $[10,12]$. This technique selectively corrodes steel which has been subject to plastic deformation and allows recovery of serial numbers which have been removed to full depth. This reagent is toxic, corrosive, is destructive - causes rusting of the steel substrate - and operational use is time-consuming and labour intensive. Chemical etching techniques have 
also been developed for non-ferrous metals $[8,15]$. These differ in reagent detail but are similar in practice to Fry's reagent.

\section{Other techniques}

Alternatives to acid-etching reagents have been listed in literature but not widely employed, due to practical limitations. Ultrasonically-induced cavitation in water can be used to etch the surface of metal [19]. Scanning Electron Microscopy (SEM) is another method for visualising and restoring serial numbers, using electron backscatter diffraction [20]. Mongan [21] reported a case where SEM was successfully used after the application of chemical etching. However, SEMs with a chamber big enough to fit a firearm are not common. Magnetic dyes have been used by Turley for serial number restoration [9]. The technique involves placing the item into a magnetic field with a magnetic ink on the surface. Iron oxide particles within the ink attach to the deformed areas of the metallic surface. The technique has been successfully used [22], but it can only be applied on magnetic material and requires sophisticated equipment.

\section{Liquid Dye Penetrants}

Originally called the "oil and whiting method", liquid dye penetrants (LDPs) were first developed in the $19^{\text {th }}$ century in railway workshops to detect flaws on iron and steel parts [23]. Items were immersed in a mixture of heavy oil and kerosene and then thoroughly cleaned. A fine suspension of chalk was applied on the surface causing oil retained in surface cracks to seep out and stain the chalk. The LDPs are applicable for the detection of discontinuities where a lack of fusion, corrosion, cracks, laps, cold shuts, and porosity are of interest [24].

The technique has been refined to improve capillary action within the cracks and discontinuities. Modern LDPs date from the mid- $20^{\text {th }}$ century and were developed to allow easy, non-destructive examination of metals for imperfections [23]. They consist of a viscous oil containing a dye. The dye may be coloured or luminescent. The LDPs work via capillary action between the oil and discontinuities/cracks in the metal, drawing the dye into them. The oil has to remain on the surface of the metal for a period of time, ensuring the dye has 
made its way into all the imperfections before the excess LDP is removed with a solvent wash or a dry rag.

\section{Aims of the study}

Liquid dye penetrants have not previously been applied to serial number restoration.

It was hypothesised that the stamping process for serial numbers would cause fractures and discontinuities in the plastic deformation zone that can be detected by LDPs. Therefore, this study aimed to explore this quick, cheap, easy to apply and non-destructive technique for serial number restoration on steel surfaces. The proposed technique was to use LDPs to highlight the imperfections created in the steel by the process of stamping a serial number, as well as to explore its potential when used in conjunction with routine techniques.

\section{Materials and Methods}

\subsection{Samples}

Eighteen steel plates with dimensions $37 \times 75 \times 6 \mathrm{~mm}$ had the serial number "842CBA" mechanically stamped into them with a force of $40 \mathrm{MN}$ to a depth of $0.6 \mathrm{~mm}$. The eighteen stamped plates were separated into three groups of six plates in order to obtain triplicates. The serial numbers were subsequently obliterated by milling the surface of the steel to various depths. Each of the six plates within a set was subjected to a progressively larger obliteration depth, ranging from $0.49-1.76 \mathrm{~mm}$.

For each steel plate, the amount of material removed during the obliteration was measured using digital callipers. The mean obliteration depth was determined by averaging four points on the sample plates. The thickness of the plate was determined using the average of four measurements per plate (Table 1).

\subsection{Chemicals and reagent preparation}

Sherwin visible dye penetrant DP-40 (400 mL), Sherwin Fluorescent dye RC-77 (400 mL) and Sherwin Developer D-100 (400 mL) were all purchased at retail in aerosol form. Cupric 
chloride (500 g) was purchased from Ajax Chemicals. 36\% Hydrochloric acid and 70\% nitric acid were purchased from RCI Labscan. Additional solvents utilised throughout the project including chloroform, acetone, ethanol and methanol were all purchased from Sigma Aldrich, Australia.

Fry's reagent was prepared by thoroughly mixing $90 \mathrm{~g}$ of cupric chloride, $100 \mathrm{~mL}$ of deionised $\mathrm{H}_{2} \mathrm{O}$ and $120 \mathrm{~mL}$ of $36 \% \mathrm{HCl}$ [12]. The second swabbing reagent was a $15 \%$ nitric acid solution that was prepared using $20 \mathrm{~mL}$ of $70 \%$ nitric acid and $93 \mathrm{~mL}$ of deionised water.

\subsection{Instrumentation}

Oven Conditions

A laboratory grade oven (Memmert, Australia) was used to investigate the influence of steel plate temperature on the performance of the LDPs. The maximum temperature investigated was $71^{\circ} \mathrm{C}$, as specified in the Safety Data Sheet for all LDPs [25]

Video Spectral Comparator

The Foster and Freeman Video Spectral Comparator (VSC6000HR) was used to capture images of the serial number restorations. For the majority of the method optimisation, white light and UV lighting at $254 \mathrm{~nm}$ were used respectively for the visible DP-40 dye penetrants and for the fluorescent RC-77 dye penetrant.

UV Viewing Cabinet

The Spectroline Model CM-10A Fluorescence Analysis Cabinet (RFSales, Australia) was used on the short wavelength $(254 \mathrm{~nm})$ setting, to determine the extent of the removal of the excess LDPs and provide quick examination of the samples exposed to the RC-77 dye penetrants.

\subsection{Procedure}

Sanding

Each steel plate containing an obliterated serial number was sanded using Flexovit Sanding sheets, with the sanding sheets ranging in grit size from 120 to 1200 . Initially, major imperfections were removed from surface of the plates with the 120 and 180 grit sheet. 
Once the deeper imperfections were removed, 600 grit sanding paper was used until there was no more visible improvement in the surface smoothness. This was followed by 800 grit sandpaper to generate a shine on the surface, after which 1200 grit sanding paper was used to generate a mirror finish on all 18 plates. Water was used to lubricate the plate to improve the sanding efficiency for obtaining a mirror finish.

LDPs application

A set of six steel plates prepared by polishing the obliterated serial number were subjected to treatment. The LDP was applied to each plate according to the variable under test, and the LDP was allowed to remain on the plate for a set period of time. The LDP was removed using a dry rag or solvent, and then the plate was immediately imaged. The various parameters tested are summarised in table 2.

\section{Fry's reagent application}

The restoration method of alternating Fry's reagent with 15\% nitric acid was evaluated on a test plate to determine its effectiveness for restoring serial numbers with the remaining plate sets. Using cotton swabs Fry's reagent and nitric acid were alternately applied to the surface using a circular motion for 10 second durations. Once the reagent was able to restore a serial number on the test plate successfully, the method was applied to selected plate sets. All of the tests involving Fry's reagent were performed at ambient temperature.

\section{Comparison procedure}

The overall procedure involved stamped and obliterated steel plates that had been sanded to a mirror finish. The plates were subjected to LDPs then examined under visible and fluorescent conditions using the VSC6000HR. The process of applying the LDPs was nondestructive, with each plate in the sets used on multiple occasions to evaluate a range of different variable combinations. At the conclusion of all LDP trials, the process of restoring the serial numbers was conducted using the well-established Fry's reagent. 
Parameters tested included subjecting the plates to heat, increasing the dwell time of the LDPs, diluting LDPs, as well as wiping methods for removing the excess dye before being examined under the VSC6000HR were all considered.

\section{Imaging technique}

The plates were first examined under white downlight and imaged, followed by white grazing light. During the image capture process, the angle of light relative to the sample was modified through small incremental changes to the axial plane with respect to the camera. Luminescent imaging was carried out using the $254 \mathrm{~nm}$ light and camera long-pass filters available on the VSC600OHR.

\section{Results and Discussion}

\subsection{Plate measurement and preparation}

Milling

It was found that the plates were not uniform in thickness and thickness varied by up to $0.1 \mathrm{~mm}$ on some of the plates. Because the milling machine was used at a set depth when obliterating the plates, the only variation in the obliteration depth should be attributable to non-uniformity of the plate or the stage. When taking the average obliteration depth measurements for a plate, there was a slight variation on each long edge. The largest obliteration depth variation within a plate was $0.075 \mathrm{~mm}$ and the smallest $0.01 \mathrm{~mm}$.

Sanding

a)

b)

Figure 2: Plate 2-4 a) before and b) after sanding to a mirror finish

When sanding the plates, the amount of material removed during the process was measured. Shown in Table 3 are the measurements recorded for Set 2 before and after sanding. From this data, the maximum amount of material removed in this set of plates was $0.09 \mathrm{~mm}$. Over-sanding the sample was a concern when using the 120 and 180 grit sanding sheets to remove the milling marks depicted in Figure 2. This becomes problematic for serial 
number restorations as sanding could reach the limit of the influenced depth, and extra sanding of the plate would result in the permanent loss of that serial number.

\subsection{Positive Control test for LDPs}

This experiment was carried out to demonstrate successful application and performance of the LDP. One test steel plate was damaged using a hammer, and RC-77 LDP applied. After removal of excess dye, the LDP successfully highlighted the damaged area (Figure 3).

Figure 3: The test plate after RC-77 LDP was applied to damaged section

\subsection{Restoration with LDPs}

No successful restorations were achieved on any of the plates using LDPs. When the dyes were applied to the polished plates, the entire mirror-smooth surface of the plate became coloured (in the case of visible dye DP-40) or fluorescent (Fluorescent dye RC-77). When the surface was wiped clean or solvent-washed to remove excess dye, the mirror surface showed no trace of dye remaining. No difference was found with variables tested including dwell time of the LDP on the surface of the plates, temperature of the LDP when applied, or method used to remove the excess LDP. There are several possible reasons for these results: Hypothesis - the plastic deformation zone contained suitable damage for development with LDPs but this was removed by polishing to a mirror finish. In contrast to restoration with Fry's reagent, it may be better to develop obliterated serial numbers using LDPs without polishing beforehand. However, to test this hypothesis, LDPs were applied on a non-sanded plate, also resulting in negative results.

Hypothesis - LDPs can only highlight cracks, and it appears that the stamping process does not produce enough damage in the plastic deformation zone of metals to be detected by LDPs. This method has no utility for restoring obliterated serial numbers. The restoration with Fry's reagent (see below) showed that the obliterated steel plates had a plastic deformation zone available for restoration, so this is a possibility. 


\subsection{Restoration with Fry's reagent}

A summary of the restorations achieved using Fry's reagent is presented in Table 4.

The plates were milled to progressively-deeper levels within each set going from plate 1 plate 6 , and the successful restorations were achieved on the plates milled to relatively shallow depths. Interestingly, it has been noticed that the visualisation angle has an effect on the imaging of the restoration. As illustrated on Figure 4, tilting the plate to an angle of $45^{\circ}$ increased the readability of the serial number.

a)

b)

Figure 4: Restoration of serial number on plate using Fry's reagent, a) no tilt, b) $45^{\circ}$ tilt

Following successful restoration with Frys reagent, the plates were polished to remove the acid etch development and treated with LDP to see whether the LDP could be a complementary restoration technique to use of Frys reagent alone. Samples were treated with LDP and heated in a laboratory oven at $70{ }^{\circ} \mathrm{C}$ for ten minutes, allowed to cool to room temperature and excess LDP removed. None of the LDP-treated plates showed any development of the obliterated serial number.

\subsection{Summary}

The LDPs tested were unable to provide any improvements to the restoration methods or assist in the enhancement of the serial number. Subsequent restoration with Fry's reagent was successful on some of the plates with relatively shallow obliteration depths. It was shown that tilting the plate helped in visualising the restored serial number.

\section{Conclusion}

The intention of using LDPs, which are commonly used as an inspection tool in the welding industry to detect cracks and imperfections, was for them to be utilised as a one-step nondestructive method for the detection of serial numbers. If successful, this would mean that the handling of harmful chemicals would not be necessary for serial number restoration. The restoration experiments using LDPs were unsuccessful; future research will continue in 
order to develop a convenient and non-destructive method of serial number restoration, but in the meantime, Fry's reagent still appears to be the most effective technique.

\section{Acknowledgements:}

The NSW Police Forensic Services Group - Forensic ballistics investigation section collaborated with the authors on this project. They assisted with the creation of the serial numbers and with their obliteration.

\section{References}

[1] da Silva L., dos Santos P. A. (2008), Recovering obliterated laser engraved serial numbers in firearms, Forensic Science International, 179, e63-6.

[2] Weber M., Weimar B. (2009), Analysis of the marking process using the finite element method, AFTE Journal, 41, 167-175.

[3] Baharum M. I., Kuppuswamy R., Rahman A. A. (2008), Recovering obliterated engraved marks on aluminium surfaces by etching technique, Forensic Science International, 177, 221-7.

[4] Polk D. E., Giessen B. C. (1989), Metallurgical aspects of serial number recovery, AFTE Journal, 21, 174-181.

[5] Abdul Wahab M. F., Mohamad Ghani N. I., Kuppuswamy R. (2012), An investigation into the suitability of some etching reagents to restoring obliterated stamped numbers on cast iron engine blocks of cars, Forensic Science International, 223, 53-63.

[6] Zaili M. A., Kuppuswamy R., Harun H. (2007), Restoration of engraved marks on steel surfaces by etching technique, Forensic Science International, 171, 27-32.

[7] Bureau of Alcohol Tobacco Firearms and Explosives (2016), Atf guidebook - importation \& verification of firearms, ammunition, and implements of war; U.S. Department of Justice, Ed.

[8] Bong Y. U., Kuppuswamy R. (2010), Revealing obliterated engraved marks on high strength aluminium alloy (aa7010) surfaces by etching technique, Forensic Science International, 195, 86-92.

[9] Turley D. M. (1987), Restoration of stamp marks on steel components by etching and magnetic techniques, Journal of Forensic Sciences, 32, 640-649.

[10] Wightman G., Matthew J. (2008), Restoration of stamp marks on steel components, Forensic Science International, 180, 32-6.

[11] Richa, Kesharwani L., Gupta A. K., Mishra M. K. (2013), Development of new reagent for restoration of erased serial number on metal plates, Egyptian Journal of Forensic Sciences, 3, 26-34.

[12] Yin S. H., Kuppuswamy R. (2009), On the sensitivity of some common metallographic reagents to restoring obliterated marks on medium carbon $(0.31 \% \mathrm{c})$ steel surfaces, Forensic Science International, 183, 50-3.

[13] Crowe G., Morgan-Smith R. (2005), Restoration of a jeweller's mark in gold jewellery, AFTE Journal, 37, 379-381.

[14] Mikko D. (1999), Griffin's reagent for serial number restoration in stainless steel, AFTE Journal, 31, 497.

[15] Brown E. W. (2001), Technical report: Serial number restoration on ruger $p$ series aluminum alloy frames, AFTE Journal, 33, 57. 
[16] Vander Voort G. F. (1999), Macrostructures, In: Metallography - principles and practice, ASM International: New York; pp 1-57.

[17] Rawdon H. S., Epstein S. (1920), Metallographic features revealed by the deep etching of steel; Technologic Papers of the Bureau of Standards: Washington; Vol. No. 156.

[18] Yatsevitch M. G. (1933), Essential factors in conducting the macroetching test under usual practical conditions of production work, Transactions American Society for Steel Treating, 21, 310-342.

[19] Young S. G. (1974), The restoration of obliterated stamped serial numbers by ultrasonically induced cavitation in water, Journal of Forensic Sciences, 19, 820-835.

[20] White R. M., Keller R. R. (2015), Restoration of firearm serial numbers with electron backscatter diffraction (ebsd), Forensic Science International, 249, 266-70.

[21] Mongan A. L. (1996), Visualization of a restored serial number using scanning electron microscopy (sem), Journal of Forensic Sciences, 41, 1074-1076.

[22] Wolfer D. A., Lee W. J. (1960), Application of magnetic principles to the restoration of serial numbers, Journal of Criminal Law, Criminology \& Police Science, 50, 519-520.

[23] Hellier C. J. (2001), Penetrant testing, In: Handbook of nondestructive evaluation, The McGraw-Hill Companies, Inc.

[24] ASTM (2016), Standard practice for liquid penetrant testing, astm international: West Conshohocken, PA; Vol. E1414 / E1417M-16.

[25] Incorporated S. (2010), Material safety data sheet- rc-77; Sherwin Incorporated: California, USA. 
Table 1: Measurements of the thickness, obliteration depth and obliteration depth beyond the stamping depth for the eighteen steel plates

\begin{tabular}{|c|c|c|c|}
\hline \multicolumn{4}{|l|}{ Set 1} \\
\hline Plate & Thickness (mm) & Obliteration depth (mm) & $\begin{array}{l}\text { Obliteration depth } \\
\text { beyond stamping } \\
(\mathrm{mm})\end{array}$ \\
\hline $1-1$ & 5.95 & 0.82 & 0.22 \\
\hline $1-2$ & 5.99 & 0.85 & 0.25 \\
\hline $1-3$ & 5.97 & 1.05 & 0.45 \\
\hline $1-4$ & 5.96 & 1.21 & 0.61 \\
\hline $1-5$ & 5.99 & 1.47 & 0.87 \\
\hline $1-6$ & 5.98 & 1.73 & 1.13 \\
\hline \multicolumn{4}{|l|}{ Set 2} \\
\hline Plate & Thickness (mm) & Obliteration depth (mm) & $\begin{array}{l}\text { Obliteration depth } \\
\text { beyond stamping } \\
(\mathrm{mm})\end{array}$ \\
\hline $2-1$ & 5.98 & 0.49 & -0.11 \\
\hline $2-2$ & 5.99 & 0.95 & 0.35 \\
\hline $2-3$ & 5.95 & 1.09 & 0.49 \\
\hline $2-4$ & 5.94 & 1.22 & 0.62 \\
\hline $2-5$ & 5.96 & 1.35 & 0.75 \\
\hline $2-6$ & 5.99 & 1.58 & 0.98 \\
\hline \multicolumn{4}{|l|}{ Set 3} \\
\hline Plate & Thickness (mm) & Obliteration depth (mm) & $\begin{array}{l}\text { Obliteration depth } \\
\text { beyond stamping } \\
(\mathrm{mm})\end{array}$ \\
\hline $3-1$ & 5.95 & 0.62 & 0.02 \\
\hline $3-2$ & 6.00 & 1.03 & 0.43 \\
\hline $3-3$ & 5.99 & 1.09 & 0.49 \\
\hline $3-4$ & 6.00 & 1.23 & 0.63 \\
\hline $3-5$ & 5.99 & 1.55 & 0.95 \\
\hline $3-6$ & 6.03 & 1.73 & 1.13 \\
\hline
\end{tabular}


Table 2: Parameters tested for the application of LDPs

\begin{tabular}{|c|c|c|c|c|c|c|c|c|}
\hline Conditions & \multicolumn{8}{|c|}{ parameters tested } \\
\hline Type of dyes & \multicolumn{4}{|l|}{ DP-40 } & \multicolumn{4}{|c|}{ RC-77 } \\
\hline Dwell times & $10 \mathrm{~min}$ & $30 \mathrm{~min}$ & $1 \mathrm{~h}$ & $2 \mathrm{~h}$ & & $24 \mathrm{~h}$ & 48 & $72 \mathrm{~h}$ \\
\hline $\begin{array}{l}\text { Application } \\
\text { temperature }\end{array}$ & \multicolumn{4}{|l|}{ ambient } & \multicolumn{4}{|c|}{$70^{\circ} \mathrm{C}$} \\
\hline LDP removal technique & dry wipe & met & anol & ethan & & ace & & $\begin{array}{l}\text { chlorofor } \\
\mathrm{m}\end{array}$ \\
\hline
\end{tabular}


Table 3: Measurements of the obliteration depth before and after sanding

\begin{tabular}{|l|l|l|l|}
\hline $\begin{array}{l}\text { Plat } \\
\text { e }\end{array}$ & $\begin{array}{l}\text { Depth before } \\
\text { sanding }(\mathrm{mm})\end{array}$ & $\begin{array}{l}\text { Depth after } \\
\text { sanding }(\mathrm{mm})\end{array}$ & $\begin{array}{l}\text { Obliteration depth } \\
\text { due to sanding }(\mathrm{mm})\end{array}$ \\
\hline $2-1$ & 0.49 & 0.49 & $<0.01$ \\
\hline $2-2$ & 0.95 & 1.04 & 0.09 \\
\hline $2-3$ & 1.09 & 1.16 & 0.07 \\
\hline $2-4$ & 1.22 & 1.23 & 0.01 \\
\hline $2-5$ & 1.35 & 1.35 & $<0.01$ \\
\hline $2-6$ & 1.58 & 1.63 & 0.05 \\
\hline
\end{tabular}


Table 4: Fry's reagent - Recovered serial numbers on all of the steel plates

\begin{tabular}{llll}
\hline Plate & Set 1 & Set 2 & Set 3 \\
\hline 1 & $\mathrm{Y}$ & $\mathrm{Y}$ & $\mathrm{Y}$ \\
2 & $\mathrm{Y}$ & $\mathrm{Y}$ & $\mathrm{N}$ \\
3 & $\mathrm{Y}$ & $\mathrm{N}$ & $\mathrm{N}$ \\
4 & $\mathrm{Y}$ & $\mathrm{N}$ & $\mathrm{N}$ \\
5 & $\mathrm{~N}$ & $\mathrm{~N}$ & $\mathrm{~N}$ \\
6 & $\mathrm{~N}$ & $\mathrm{~N}$ & $\mathrm{~N}$ \\
\hline
\end{tabular}

